\title{
Effects of peer influence on dietary intake and physical activity in schoolchildren
}

\author{
Tara Finnerty*, Sue Reeves, Jaqueline Dabinett, Yvonne M Jeanes and Claus Vögele \\ School of Human and Life Sciences, Roehampton University, Holybourne Avenue, London SW15 4JD, UK
}

Submitted 3 July 2008: Accepted 17 July 2009: First published online 1 September 2009

\begin{abstract}
Objective: To investigate the dietary intake and physical activity of boys and girls aged 9-13 years, and the influence of peers on these behaviours.

Design: Cross-sectional study.

Setting: Nine primary and secondary schools in south-west London.

Subjects: A total of 315 children wore sealed pedometers, provided self-report measures of dietary intake and answered a questionnaire relating to peer influence. Anthropometric measures of height and weight were also obtained.

Results: Obese children had the lowest reported energy intakes and the lowest step counts per day. Boys took significantly more steps per day than girls, however girls were closer to achieving their recommended cut-offs for physical activity. Girls had lower energy intakes per day and lower BMI Z-scores than boys, however both genders, across all age groups, had higher than recommended intakes of saturated fat. There were significant associations between peer influence and physical activity levels but not between peer influence and dietary intake.

Conclusions: Low energy intake and physical activity levels but high saturated fat intakes among boys and girls across all age groups highlight the importance of promoting both physical activity and healthy food choices. The finding that peers have a significant effect on physical activity levels but not on dietary intake offers an important approach for the design of health promotion interventions and obesity prevention programmes. Such designs may be particularly beneficial for obese youth, since the low physical activity levels found could be a major contributing factor to the maintenance of the condition.
\end{abstract}

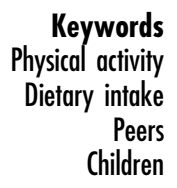

Several studies have identified a rising prevalence of overweight and obesity in British schoolchildren ${ }^{(1-3)}$, with particular concern given to the high levels among children in London ${ }^{(4)}$. As diet and physical activity both play a significant role in the onset and development of obesity $^{(5)}$ and in the maintenance of health of young people ${ }^{(6,7)}$, it is surprising that research combining dietary intake and objectively measured physical activity in children and adolescents from the UK remains inadequate.

British adolescents are recognised as having some of the worst eating habits in Europe ${ }^{(8)}$. Yet, since evidence suggests energy intake to have declined in this age group ${ }^{(9)}$, rising obesity levels may be partly explained by a decrease in physical activity, resulting in a positive energy balance. Because of the lack of population-based objective data describing levels of children's activity, in the $\mathrm{UK}^{(10)}$, it is difficult to establish whether such a decline is actually taking place. Furthermore, although not all children with poor dietary and physical activity habits may currently be overweight or obese, these young people may be putting themselves at risk for other adverse health conditions ${ }^{(11)}$.
Lack of research in this area also constitutes a cause for concern for future health status, as diet and activity patterns established during childhood and adolescence have been recognised as playing a significant role in the onset of chronic disease occurrences in later life ${ }^{(12,13)}$. With food and activity habits adopted during this life stage also found to track into adulthood ${ }^{(14,15)}$, the importance of investigating such lifestyle behaviours during the childhood years is crucial, in order to ascertain the most effective ages at which to intervene. A better understanding of the factors determining health behaviours in children and adolescents is, therefore, mandatory not only for better health in youth but also for the prevention of ill-health in adulthood.

Research $^{(16)}$ has shown the family to be a strong determinant of dietary behaviours, but as children grow older they spend increasing amounts of time with friends and the influence of peers may play a more important role in their lifestyle choices. However, the role of the peer group in influencing food choice ${ }^{(17)}$ and physical activity ${ }^{(18)}$ among school children has rarely been examined in 
the UK. The aim of the present study was therefore to investigate levels of physical activity and dietary intake of boys and girls and to explore any effects of peers on these behaviours.

\section{Methods}

\section{Setting and participants}

The findings of the present survey are part of an ongoing longitudinal study. Consequently, the power calculation for subject numbers was based on change of physical activity at 9 years, compared with 14 years, from Berkey et al.'s ${ }^{(12)}$ longitudinal research. A minimum of 100 volunteers within each age group were initially required and recruited.

Four hundred and three children (216 boys and 187 girls) between the ages of 10 and 13 years (mean 11.4 (SD 1.1) years), who were in full-time education in three primary schools and six secondary schools that ranged from mid to high socio-economic backgrounds in south-west London, were recruited. Due to absenteeism, drop-out and apparatus-related issues such as loss of pedometers or incomplete diary completion, 315 (162 boys, 153 girls) completed all aspects of the study.

To select schools, a one-stage cluster sampling method was used to overcome the constraints of time and costs associated with a dispersed population. The predetermined clusters included: (i) type of school; (ii) school geographic location; (iii) gender make-up of the school; (iv) secondary school feeding system (due to an associated longitudinal study that was also taking place); and (v) school classification. The study was approved by the Ethics Committee of Roehampton University and permission of the head teacher was received from each participating school. Each child gave informed consent and parental consent was obtained prior to the child's participation in the study.

\section{Measurements}

All data were collected by trained researchers and all participants were given clear instructions regarding their involvement. In case any questions arose throughout the duration of data collection, the contact details of the lead researcher were also given. Questionnaires were all completed confidentially under supervision in classrooms or in designated areas; to ensure anonymity throughout the study, each participant was given an ID number.

\section{Dietary intake}

Dietary intake was measured with a $3 \mathrm{~d}$ diary. This included measurements taken over one weekday and two weekend days. These days were chosen in order to obtain an accurate insight into the children's food intake. Work by de Castro ${ }^{(19)}$ has recognised that there is often greater variation in food intake over the weekend compared with weekdays and this chosen method had the added benefit of limiting interference with the school day as much as possible. Participants were instructed to record all food, drink and portion sizes with as much detail as possible. The diary also contained prompts, e.g. 'What did you have for breakfast?' and 'Did you have any snacks today?', in order to make the process as clear as possible. The $3 \mathrm{~d}$ food diary has been recognised as a valid nutritional tool to measure dietary intake in 10- to 13 -year-olds ${ }^{(20)}$ and children as young as 8 years of age are recognised to reliably report food intake ${ }^{(21)}$.

\section{Pbysical activity}

At the same time as completing the food diary, participants were asked to complete (either on their own or with the assistance of an adult) a $3 \mathrm{~d}$ activity diary, detailing all activities undertaken and their duration. Participants were asked to carry these diaries with them at all times, so that they could input any physical activity undertaken as soon as possible after the event. Explanations and examples of how to complete the diary correctly were given by the lead researcher at the time of diary distribution. Subjects were also asked to wear a sealed pedometer (Yamax Digiwalker SW-200; Yamasa, Tokyo, Japan), only to be removed during bathing, swimming and sleeping. Participants were asked to go about their everyday activities as normal and not to tamper with the pedometer throughout the $3 \mathrm{~d}$ monitoring period. Researchers sealed the pedometers on site and placed them on participants on day 1 of the monitoring period and removed them on day 3. The Yamax Digiwalker SW series has consistently been found among the most accurate of pedometers ${ }^{(22-26)}$, and the Yamax SW-200 is recommended as a reliable monitor for use in children $^{(27,28)}$.

Instructions were given on how to wear the sealed pedometer correctly and record any times in which it was taken on or off. In line with other researchers in the field ${ }^{(6,29)}$, if a pedometer was removed for more than $1 \mathrm{~h}$ in any one day, those results were omitted from analysis.

\section{Height and weight}

Weight and height measurements were taken to the nearest $0 \cdot 1 \mathrm{~kg}$ and $0 \cdot 1 \mathrm{~cm}$ respectively, using the Omron M5-1 Intellisense (Kyoto, Japan) weighing scales and a Leicester (Crawlea Medical, Birmingham, UK) free-standing stadiometer. All participants were instructed to remove their shoes and any other heavy outer garments before measurement. BMI $\left(\mathrm{kg} / \mathrm{m}^{2}\right)$ and BMI $Z$-score were then calculated using equations based on UK reference data ${ }^{(30)}$.

\section{Peer influence}

Peer influence was measured with a questionnaire adapted from Sallis et al.'s ${ }^{(31)}$ validated Social Support and Eating Habits/Exercise Survey, and contained questions relating to both physical activity and dietary intake 
and the effect of peers on these behaviours. Typical questions included: 'During the past three months, my friends': (i) 'encouraged me not to eat "unhealthy foods" (cake, crisps, sweets, chocolate) when I was tempted to do so'; (ii) 'ate "unhealthy foods" (cake, crisps, sweets, chocolate) in front of me'; (iii) 'got angry when I encouraged them not to eat "unhealthy foods" (cake, crisps, sweets, chocolate)'; (iv) 'participated in physical activity or exercise with me'; (v) 'gave me helpful reminders to be physically active or exercise'; and (v) 'criticised me or made fun of me for being physically active or exercising'. The questionnaires, which were administered on day 1 of the survey, were piloted to ensure relevance and comprehension with schoolchildren aged at least 10 years, who were not involved in the study.

\section{Data analysis}

Since the data were not normally distributed, nonparametric data analyses were undertaken. Food diary analysis was conducted using DietPlan 6 (Forestfield Software, Horsham, UK) and non-parametric data analyses using the SPSS statistical software package version 15.0 (SPSS Inc., Chicago, IL, USA). Spearman's correlation was used to investigate bivariate relationships between the variables and Mann-Whitney tests were used to investigate differences between genders for all variables. Kruskal-Wallis tests were used to investigate differences between the three age groups (age group 1 = 9-10 years; age group $2=11-12$ years; age group $3=13-14$ years) for each dependent variable; both of these tests are for independent levels within a single factor.

Standardised BMI scores ( $Z$-scores) were calculated using Pan and Cole's ${ }^{(32)}$ Microsoft ${ }^{\circledR}$ Excel add-in 'ImsGrowth' package. These scores represent the degree to which each child deviates from their age- and gender-specific median $^{(33)}$, using equations based on UK reference data $^{(30)}$. The 'ImsGrowth' package also enables graded levels of thinness, normal weight, overweight and obesity of participants to be calculated, based on pooled international data for BMI (UK data included) ${ }^{(34)}$, and is linked to the WHO recommended adult cut-off points. This allows for direct comparisons of body composition in children and adolescents worldwide.

\section{Results}

\section{Physical activity}

Boys took significantly more steps per day than girls ( $P \leq 0 \cdot 05$; Table 1 ) but depending on the recommended health cut-offs used ${ }^{(29,35)}$, only $23 \%^{(29)}$ (or $19 \%^{(35)}$ ) of boys reached the recommended health cut-offs of $15000^{(29)}$ (or $16000^{(35)}$ ) steps per day and only $29 \%{ }^{(29)}$ (or $21 \%{ }^{(35)}$ ) of girls reached their recommended $12000^{(29)}$ (or $13000^{(35)}$ ) steps per day. There were significant positive correlations between the number of steps taken per day and: (i) friends taking part in physical activity or exercise with the participant $(r=0 \cdot 121$; $P \leq 0.05$ ); and (ii) friends discussing physical activity or exercise with the participant $(r=0 \cdot 116 ; P \leq 0 \cdot 05)$.

\section{Dietary intake}

Boys had a significantly higher daily energy intake than girls ( $P \leq 0 \cdot 05$; Table 1 ) but self-reported energy intake for both genders was substantially less than the Reference Nutrient Intake (RNI) ${ }^{(36)}$ and the most recent national food survey of children and adolescents aged 11-14 years (National Diet and Nutrition Survey) ${ }^{(37)}$. Fat and carbohydrate intakes for both boys and girls were below recommendations (RNI; Table 2$)^{(36)}$, with protein being the

Table 1 Descriptive characteristics of mean pedometer-measured steps per day, daily energy intake, BMI and BMI Z-scores by gender: boys and girls aged 9 to 13 years, south-west London, UK

\begin{tabular}{|c|c|c|c|c|c|c|c|c|}
\hline \multirow[b]{2}{*}{ Gender } & \multicolumn{2}{|c|}{ Steps/d } & \multicolumn{2}{|c|}{ Energy intake $(\mathrm{kJ} / \mathrm{d})$} & \multicolumn{2}{|c|}{ BMI $\left(\mathrm{kg} / \mathrm{m}^{2}\right)$} & \multicolumn{2}{|c|}{ BMI Z-score } \\
\hline & Mean & SD & Mean & SD & Mean & SD & Mean & SD \\
\hline Boys and girls ( $n$ 315) & 11005 & 4507 & 6460 & 2013 & $18 \cdot 87$ & 3.38 & 0.27 & $1 \cdot 12$ \\
\hline Boys $(n 162)$ & 11910 & 4785 & 6728 & 2054 & $18 \cdot 89$ & $2 \cdot 83$ & 0.38 & 0.98 \\
\hline Girls ( $n$ 153) & 10180 & 3987 & 6180 & 1933 & $18 \cdot 84$ & 3.92 & $0 \cdot 13$ & 0.24 \\
\hline
\end{tabular}

Table 2 Mean daily macronutrient intake in the study sample compared with the Reference Nutrient Intake (RNI) and the National Diet and Nutrition Survey (NDNS): boys and girls aged 9 to 13 years, south-west London, UK

\begin{tabular}{|c|c|c|c|c|c|c|c|c|}
\hline \multirow[b]{3}{*}{ Macronutrient } & \multicolumn{4}{|c|}{ Study sample } & & & & \\
\hline & \multicolumn{2}{|c|}{ Boys } & \multicolumn{2}{|c|}{ Girls } & \multicolumn{2}{|c|}{$\mathrm{RNI}^{(36)}$ (11-14 years) } & \multicolumn{2}{|c|}{$\operatorname{NDNS}^{(37)}$ (11-14 years) } \\
\hline & Mean & SD & Mean & SD & Boys & Girls & Boys & Girls \\
\hline Fat $(\mathrm{g} / \mathrm{d})$ & 47 & $31 \cdot 2$ & 46 & $27 \cdot 6$ & 74 & 72 & 77 & 67 \\
\hline Saturated fat (\% of energy) & $13 \cdot 3$ & $3 \cdot 0$ & $13 \cdot 4$ & $3 \cdot 1$ & 11 & 11 & 14 & 14 \\
\hline Carbohydrate $(\mathrm{g} / \mathrm{d})$ & 169 & $123 \cdot 2$ & 174 & $124 \cdot 4$ & 340 & 276 & 271 & 228 \\
\hline Protein $(\mathrm{g} / \mathrm{d})$ & 42 & $27 \cdot 2$ & 43 & $23 \cdot 7$ & 42 & 41 & 64 & 53 \\
\hline
\end{tabular}


only macronutrient in both genders that met or exceeded the recommended intake $(\mathrm{RNI}=42 \mathrm{~g}$ for boys; $\mathrm{RNI}=41 \mathrm{~g}$ for girls $)^{(36)}$. All macronutrients were also below values for age-comparable UK children (Table 2) ${ }^{(37)}$. However, when analysing saturated fat intake as a percentage of total energy, values for both boys and girls were above those recommended (11\%; Table 2$)^{(36)}$ but below those found for age-comparable UK children (Table 2) ${ }^{(37)}$. There was no association between peer influence and dietary intake.

To assess for reporting error as a result of self-report measures, fruit and vegetable intake recorded in diaries was cross-validated with a Fruit and Vegetables Screening Measure ${ }^{(38)}$ and a positive correlation $(r=0.43)$ was revealed $^{(39)}$.

\section{BMI Z-score}

According to BMI international grades ${ }^{(32,40)}$, male and female obese individuals had the lowest energy intakes (Table 3) and lowest total step counts per day (Table 4). Boys had significantly higher BMI $Z$-scores than girls $(P \leq 0 \cdot 05$; Table 1$)$ and according to UK reference data $^{(30)}$, both genders' mean BMI $Z$-scores were within the 'normal' weight category. Using international grades $^{(32,40)}$, the prevalence of overweight and obesity in the present sample was $13 \%$ and $5 \%$. Although $80 \%$ of boys and $72 \%$ of girls were classified 'normal' weight, $9 \%$ of girls were classified as 'thin'.

\section{Peer acceptance}

There were significant positive correlations between perceived peer acceptance and: (i) total number of steps per day $(r=0.111 ; P \leq 0 \cdot 05)$; (ii) friends taking part in physical activity or exercise with the participant $(r=$ 0.283 ; $P \leq 0 \cdot 01)$; (iii) friends offering to take part in physical activity or exercise with the participant $(r=$ $0 \cdot 186 ; P \leq 0 \cdot 01)$; (iv) friends walking to school with the participant $(r=0 \cdot 158 ; P \leq 0 \cdot 01)$; (v) friends discussing physical activity with the participant $(r=0 \cdot 140 ; P \leq 0 \cdot 01)$; (vi) friends changing their schedule so that they could be physically active together $(r=0 \cdot 117 ; P \leq 0 \cdot 05$ ); (vii) friends giving them helpful reminders to be active ( $r=0 \cdot 189 ; \quad P \leq 0 \cdot 01$ ); (viii) friends talking about how much they like to be physically active or exercising ( $r=0 \cdot 242 ; P \leq 0 \cdot 01$ ); and (ix) friends planning physical activity on day trips together $(r=0 \cdot 227 ; P \leq 0 \cdot 01)$.

There were significant negative correlations between BMI $Z$-score and: (i) perceived peer acceptance ( $r=-0 \cdot 134 ; P \leq 0 \cdot 05$ ); and (ii) daily portions of fruit and vegetables consumed $(r=-0 \cdot 123 ; P \leq 0 \cdot 05)$.

\section{Age group}

Table 5 shows descriptive characteristics of the present sample by age group. Overall, there were no significant differences in daily energy intake or saturated fat intake

Table 3 Mean daily total energy intake according to BMI international grade and gender: boys and girls aged 9 to 13 years, south-west London, UK

\begin{tabular}{|c|c|c|c|c|c|c|c|}
\hline \multirow[b]{3}{*}{ BMI international grade } & \multicolumn{7}{|c|}{ Energy intake $(\mathrm{kJ} / \mathrm{d})$} \\
\hline & \multicolumn{2}{|c|}{ Whole group } & \multicolumn{2}{|c|}{ Boys } & \multicolumn{3}{|c|}{ Girls } \\
\hline & Mean & SD & Mean & SD & Mean & & SD \\
\hline Thinness grade $1\left(\mathrm{BMI}=17 \cdot 0-<18 \cdot 5 \mathrm{~kg} / \mathrm{m}^{2}\right)$ & 5941 & 2176 & 5749 & 707 & 5983 & $(n 14)$ & 640 \\
\hline Normal weight $\left(\mathrm{BMI}=18 \cdot 5-<25 \cdot 0 \mathrm{~kg} / \mathrm{m}^{2}\right)$ & 6619 & 2042 & 6937 & 2109 & 6234 & (n 108) & 1895 \\
\hline Overweight $\left(\mathrm{BMI}=25 \cdot 0-<30 \cdot 0 \mathrm{~kg} / \mathrm{m}^{2}\right)$ & 6155 & 1791 & 6100 & 1686 & 6234 & $(n 17)$ & 1979 \\
\hline Obese $\left(\mathrm{BMI} \geq 30 \cdot 0 \mathrm{~kg} / \mathrm{m}^{2}\right)$ & 5318 & 1753 & 5301 & 1464 & 5330 & & 2013 \\
\hline
\end{tabular}

Table 4 Mean total number of steps per day according to BMI international grade and gender: boys and girls aged 9 to 13 years, south-west London, UK

\begin{tabular}{|c|c|c|c|c|c|c|c|}
\hline \multirow[b]{3}{*}{ BMI international grade } & \multicolumn{7}{|c|}{ Steps/d } \\
\hline & \multicolumn{2}{|c|}{ Whole group } & \multicolumn{2}{|c|}{ Boys } & \multicolumn{3}{|c|}{ Girls } \\
\hline & Mean & SD & Mean & SD & Mean & & SD \\
\hline Thinness grade $1\left(\mathrm{BMI}=17 \cdot 0-<18 \cdot 5 \mathrm{~kg} / \mathrm{m}^{2}\right)$ & \multicolumn{2}{|c|}{$(n 17)$} & \multicolumn{2}{|c|}{$(n 3)$} & 11609 & $(n 14)$ & 3648 \\
\hline Normal weight $\left(\mathrm{BMI}=18 \cdot 5-<25 \cdot 0 \mathrm{~kg} / \mathrm{m}^{2}\right)$ & \multicolumn{2}{|c|}{$11259{ }_{(n 241)} 4597$} & \multicolumn{2}{|c|}{$(n$ 128) } & 10349 & $(n 113)$ & 3989 \\
\hline Overweight $\left(\mathrm{BMI}=25 \cdot 0-<30 \cdot 0 \mathrm{~kg} / \mathrm{m}^{2}\right)$ & 10531 & 3923 & 11036 & 4102 & 9858 & $(n 18)$ & 3677 \\
\hline Obese $\left(\mathrm{BMI} \geq 30 \cdot 0 \mathrm{~kg} / \mathrm{m}^{2}\right)$ & 9040 & 4754 & 10976 & 4882 & 7879 & $(n 10)$ & 4520 \\
\hline
\end{tabular}


Table 5 Descriptive characteristics of mean pedometer-measured steps per day, daily energy intake, daily saturated fat intake, BMI and BMI Z-score by age group and gender: boys and girls aged 9 to 13 years, south-west London, UK

\begin{tabular}{|c|c|c|c|c|c|c|c|c|c|c|c|}
\hline \multirow[b]{2}{*}{ Gender } & \multirow{2}{*}{$\begin{array}{l}\text { Age group } \\
\text { (years) }\end{array}$} & \multicolumn{2}{|c|}{ Steps/d } & \multicolumn{2}{|c|}{$\mathrm{BMI}\left(\mathrm{kg} / \mathrm{m}^{2}\right)$} & \multicolumn{2}{|c|}{ BMI Z-score } & \multicolumn{2}{|c|}{ Energy intake (kJ/d) } & \multicolumn{2}{|c|}{ Saturated fat (\% of energy) } \\
\hline & & Mean & $\mathrm{SD}$ & Mean & SD & Mean & SD & Mean & SD & Mean & SD \\
\hline Boys and girls ( $n$ 95) & $9-10$ & 11748 & 4452 & $17 \cdot 1$ & $2 \cdot 27$ & -0.07 & $1 \cdot 00$ & 6757 & 2210 & $12 \cdot 9$ & $2 \cdot 9$ \\
\hline Boys $(n 40)$ & $9-10$ & 12443 & 5252 & $17 \cdot 6$ & $2 \cdot 40$ & 0.22 & 0.96 & 7117 & 2184 & $12 \cdot 6$ & $3 \cdot 1$ \\
\hline Girls ( $n 55)$ & $9-10$ & 11290 & 3819 & $16 \cdot 8$ & $2 \cdot 14$ & -0.29 & 0.99 & 6485 & 2218 & $13 \cdot 0$ & $2 \cdot 8$ \\
\hline Boys and girls ( $n$ 204) & $11-12$ & 10692 & 4703 & $19 \cdot 5$ & $3 \cdot 69$ & 0.46 & $1 \cdot 14$ & 6251 & 1933 & $13 \cdot 6$ & $3 \cdot 1$ \\
\hline Boys $(n 100)$ & $11-12$ & 11822 & 5209 & $19 \cdot 1$ & $2 \cdot 82$ & 0.53 & 0.93 & 6376 & 2051 & $13 \cdot 7$ & $3 \cdot 0$ \\
\hline Girls (n 104) & $11-12$ & 9681 & 3961 & $19 \cdot 9$ & $4 \cdot 35$ & 0.39 & $1 \cdot 31$ & 6142 & 1833 & $13 \cdot 5$ & $3 \cdot 2$ \\
\hline Boys and girls $(n 67)$ & $13-14$ & 11211 & 3573 & $19 \cdot 3$ & $2 \cdot 85$ & $0 \cdot 17$ & 1.09 & 6715 & 1892 & $13 \cdot 3$ & $2 \cdot 9$ \\
\hline Boys ( $n 55)$ & $13-14$ & 11596 & 3360 & $19 \cdot 4$ & $2 \cdot 90$ & 0.26 & 1.07 & 7046 & 1904 & $13 \cdot 0$ & $2 \cdot 7$ \\
\hline Girls ( $n$ 12) & $13-14$ & 9778 & 4131 & $18 \cdot 9$ & $2 \cdot 68$ & -0.24 & $1 \cdot 17$ & 5230 & 879 & $14 \cdot 8$ & $3 \cdot 2$ \\
\hline
\end{tabular}

between age groups, but a significant difference was found in number of steps per day $(P \leq 0.05)$ and BMI $Z$-score $(P \leq 0 \cdot 01)$, with the youngest age group having the highest number of steps per day and the lowest BMI $Z$-scores. In boys only, daily energy intake was also significantly higher in the youngest age group $(P \leq 0 \cdot 05)$. Additionally, although boys had significantly higher daily energy intakes than girls $(P \leq 0 \cdot 05)$, they were further away from their RNI than girls in age groups 1 (9-10 years) and 2 (11-12 years).

\section{Gender differences}

In girls but not boys, there was a significant positive correlation between number of steps per day and: (i) peer acceptance $(r=0 \cdot 165 ; P \leq 0 \cdot 05)$; and (ii) daily portions of fruit and vegetables $(r=0 \cdot 168 ; P \leq 0 \cdot 05)$. There was also a significant negative correlation between BMI $Z$-scores and number of steps per day $(r=-0 \cdot 193 ; P \leq 0 \cdot 05)$.

In boys, BMI $Z$-scores and peer acceptance showed an inverse association $(r=-0 \cdot 200 ; P \leq 0 \cdot 01)$, whereas there was a significant positive correlation between peer acceptance and daily portions of fruit and vegetables $(r=0 \cdot 308 ; P \leq 0 \cdot 01)$.

\section{Discussion}

The present study investigated levels of physical activity and dietary intake in boys and girls aged 10-13 years, and the influence of peers on these behaviours. The results show low energy intake and physical activity levels but high intakes of saturated fat in boys and girls across all age groups. There were significant associations between peer influence and physical activity levels but not between peer influence and dietary intake.

Up to one-third of English children are already overweight and obese ${ }^{(4)}$ and if no action is taken, researchers believe that one child in five aged 2-15 years in England will be obese by $2010^{(41)}$. Such a condition results in a higher risk of premature illness and death later in life ${ }^{(9)}$, with one study finding overweight in childhood to double the risk of developing CHD in adulthood ${ }^{(42)}$. Although the majority of participants involved in the present study had BMI $Z$-scores that were recognised as 'normal' (80\%), the prevalence of overweight was disconcerting at $13 \%$ and obesity at $5 \%$. Consequently, public health concerns have resulted in interventions and recommendations being introduced to curb such levels, with many focusing primarily on a reduction in energy intake ${ }^{(43,44)}$.

In line with similar research in English schoolchildren $^{(6)}$, both boys and girls in the present sample did not engage in recommended physical activity levels. Previously, across many Westernised countries, there has been warranted concern regarding girls' physical activity levels ${ }^{(44-47)}$. Yet, the current study has produced an interesting new finding regarding boys' participation levels, with girls' mean daily step counts being far closer to their gender-specific cut-off for health. This potentially creates an important new angle for the design of genderspecific interventions in the future.

The low levels of energy intake in girls in all age groups and the fact that $9 \%$ of girls were classified as 'thin' constitute a cause for concern, as these girls may be putting themselves at risk by undertaking unhealthy weight-management strategies. Such dietary behaviour has been identified as a risk factor for eating disorders ${ }^{(48)}$. Furthermore, the observed decline in energy intake across age groups in boys only is an interesting new finding, which has previously been reported only for girls ${ }^{(49,50)}$ during this life stage. If it can be established that this decline continues throughout adolescence, genderspecific health promotion strategies will be needed.

Low energy intake was evident across all study participants, which may indicate undernutrition. This, however, is unlikely, since the majority of participants were within the 'normal' range for BMI Z-scores. Underreporting may therefore be an issue, recognised elsewhere as a prevalent problem in nutritional research involving school children ${ }^{(51)}$. Until more practical, costeffective methods to assess child and adolescent total energy intake over time are made available, it may be more useful to investigate the types of food they are consuming, as the higher than recommended intakes of saturated fat among both boys and girls across all age 
groups suggest that food type rather than total energy intake may be playing a more significant role in young people's health status.

The negative correlations between BMI Z-score and peer acceptance and daily portions of fruit and vegetables, indicate that those children with greater BMI ( $Z$-scores), perhaps as a result of a less healthy diet, feel less accepted by their peers. Negative feelings by peers towards overweight and obese children have been reported previously ${ }^{(52,53)}$, and contribute to low selfesteem, depression and body dissatisfaction ${ }^{(9)}$, which may further contribute to the consumption of a poor diet with fewer healthy foods (fruit and vegetables). Using the school environment to promote self-esteem at the same time as educating children from a young age on the importance of physical activity, could be an effective way to address these issues. It would be also interesting to ascertain whether these correlations continue as children grow older, which may consequently introduce a new angle of approach for lifestyle interventions.

Since adolescence is recognised as a time when young people seek peer approval and social identity, it has been hypothesised that the influence of peers plays a significant role in food acceptability and selection, and there is evidence in support of this notion ${ }^{(54-56)}$. However, this could not be replicated in the current study, and this is corroborated by findings by French and colleagues ${ }^{(57)}$, who found friend's influence to be the least important motivator for snack choice among American adolescents. Furthermore, the finding that peers do not play a role in dietary behaviour in younger childhood (from 10 years onwards) is an important finding for researchers who are interested in examining potential social influences on dietary behaviour in young people. Additional research investigating whether other forms of social support (siblings, teachers, parents) play an interchangeable role in food choice selection as children grow older is, therefore, warranted.

Peers did, however, influence physical activity behaviour in the current study. This is in line with previous research $^{(18,58)}$ and highlights the notion that in order to prevent an obesogenic environment, it is important not only to promote physical activity among young people but also to involve their wider network of peers in this process. At the same time, educating children from a young age on the importance of healthy food choices may help promote healthy lifestyle behaviours that not only prevent weight gain but also prevent unhealthy weight-loss strategies that may also be playing a significant role in the well-being of our nation's youth.

\section{Limitations}

The limitations of the present study include its crosssectional design and the risk of measurement bias for selfreport measures of dietary intake, physical activity and peer influence. In particular, considering that under-reporting was likely, the true results for saturated fat intake may actually be higher, which constitutes a cause for concern. Yet, a number of measures were taken to try and reduce these bias and included: (i) the use of sealed pedometers; (ii) the use of a validated Fruit and Vegetable Screening Measure for Adolescents ${ }^{(38)}$; and (iii) the use of a reliable and valid questionnaire ${ }^{(31)}$ to source all questions related to peer influence. By undertaking longitudinal research, the interactive relationships that have been revealed will also be examined further over time, which may provide a new dimension with which to design more effective interventions to promote healthy lifestyle behaviours in school children.

\section{Conclusions}

The present results indicate that the majority of participants were within the normal body composition range but had low energy intakes and physical activity levels and high intakes of saturated fat. In order to try and tackle these poor lifestyle behaviours, education regarding healthy food choices is necessary. Improved techniques that identify under-reporting in the young should also be made available. New physical activity interventions are warranted for boys and girls younger than 9 years of age and should incorporate child and adolescent peer groups. Such designs may be particularly beneficial for obese youth, since the low physical activity levels found could be a major contributing factor to the maintenance of the condition $^{(59)}$.

\section{Acknowledgements}

The authors were supported by a grant from the Human and Life Sciences Research Fund at Roehampton University. No conflicts of interest are declared. T.F. is the corresponding author and S.R., J.D., Y.M.J. and C.V. offered additional contributions to the manuscript. The authors acknowledge Dr Andrew Head for his statistical assistance.

\section{References}

1. Chinn S \& Rona R (2001) Prevalence and trends in overweight and obesity in three cross sectional studies of British children, 1974-94. BMJ 322, 24-26.

2. McCarthy H, Ellis S \& Cole T (2003) Central overweight and obesity in British youth aged 11-16 years: cross sectional surveys of waist circumference. BMJ 326, 624.

3. Rudolf M, Greenwood D \& Cole T (2004) Rising obesity and expanding waistlines in schoolchildren: a cohort study. Arch Dis Child 89, 235-237.

4. Department of Health (2003) Health Survey for England. London: The Stationary Office; available at http:// www.dh.gov.uk/en/Publicationsandstatistics/Publications/ PublicationsStatistics/DH_4078027

5. Zapata L, Bryant C, McDermott R \& Hefelfinger J (2008) Dietary and physical activity behaviors of middle school 
youth: the Youth Physical Activity and Nutrition Survey. J Sch Health 78, 9-18.

6. Duncan M, Al-Nakeeb Y, Woodfield L \& Lyons M (2007) Pedometer determined physical activity levels in primary school children from central England. Prev Med 44, 416-420.

7. Gibson S \& Neate D (2007) Sugar intake, soft drink consumption and body weight among British children: further analysis of National Diet and Nutrition Survey data with adjustment for under-reporting and physical activity. Int J Food Sci Nutr 58, 445-460.

8. Vereecken C, De Henauw S \& Maes L (2005) Adolescents' food habits: results of the Health Behaviour in School-aged Children survey. Br J Nutr 94, 423-431.

9. Sweeting H (2008) Gendered dimensions of obesity in childhood and adolescence. Nutr J 7, 1; available at http:// www.nutritionj.com/content/7/1/1

10. Riddoch C, Mattocks C, Deere K, Saunders J, Kirkby J, Tilling K, Leary S, Blair S \& Ness A (2007) Objective measurement of levels and patterns of physical activity. Arch Dis Child 92, 963-969.

11. World Health Organization (2005) The European Health Report: Public Health Action for Healthier Children and Populations. Copenhagen: WHO Regional Office for Europe; available at http://www.euro.who.int/ehr2005

12. Berkey C, Rockett H, Field A, Gillman M, Frazier L, Camargo C \& Colditz G (2000) Activity, dietary intake, and weight changes in a longitudinal study of preadolescent and adolescent boys and girls. Pediatrics 105, e56; available at http://pediatrics.aappublications.org/cgi/content/ abstract/105/4/e56

13. Baranowski T (2004) Why combine diet and physical activity in the same international research society? Int $J$ Behav Nutr Phys Act 1, 2; available at http://www. ijbnpa.org/content/1/1/2

14. Lien N, Lytle L \& Klepp K (2001) Stability in consumption of fruit, vegetables, and sugary foods in a cohort from age 14 to age 21. Prev Med 33, 217-226.

15. Harro M \& Riddoch C (2000) Physical activity. In Paediatric Exercise Science and Medicine, vol. 1, pp. 77-84 [ $\mathrm{N}$ Armstrong and $\mathrm{W}$ Van Mechelen, editors]. Oxford: Oxford University Press.

16. Wake Y (2008) Nutrition and the role of the family. Complete Nutr 8, 9-11.

17. Story M, Neumark-Sztainer D \& French S (2002) Individual and environmental influences on adolescent eating behaviors. J Am Diet Assoc 102, 3 Suppl., S40-S51.

18. Springer A, Kelder S \& Hoelscher D (2006) Social support, physical activity and sedentary behaviour among 6th grade girls: a cross-sectional study. Int J Behav Nutr Phys Act 3, 8; available at http://www.ijbnpa.org/content/3/1/8

19. De Castro J (1991) Weekly rhythms of spontaneous nutrient intake and meal pattern of humans. Physiol Behav 50, 729-738.

20. Rockett H \& Colditz G (1997) Assessing diets of children and adolescents. Am J Clin Nutr 65, 1116-1122.

21. Sobo E, Rock C, Neuhouser M, Maciel T \& NeumarkStzainer D (2000) Caretaker-child interaction during children's 24-hour dietary recalls: who contributes what to the recall report? J Am Diet Assoc 100, 428-433.

22. Bassett D, Ainsworth B, Leggett S, Mathien C, Main J, Hunter D \& Duncan G (1996) Accuracy of five electronic pedometers for measuring distance walked. Med Sci Sports Exerc 28, 1071-1077.

23. Crouter S, Schneider P, Karabulut M \& Bassett D (2003) Validity of 10 electronic pedometers for measuring steps, distance, and energy cost. Med Sci Sports Exerc 35, $1455-1460$.

24. Schneider P, Crouter S, Lukajic O \& Bassett D (2003) Accuracy and reliability of 10 pedometers for measuring steps over a $400 \mathrm{~m}$ walk. Med Sci Sports Exerc 35, 1779-1784.

25. Le Masurier G \& Tudor-Locke C (2003) Comparison of pedometer and accelerometer accuracy under controlled conditions. Med Sci Sports Exerc 35, 867-871.

26. Schneider P, Crouter S \& Bassett D (2004) Pedometer measures of free-living physical activity: comparison of 13 models. Med Sci Sports Exerc 36, 331-335.

27. Kilanowski C, Consalvi A \& Epstein L (1999) Validation of an electronic pedometer for measurement of physical activity in children. Pediatr Exerc Sci 11, 63-68.

28. Barfield J, Rowe D \& Michael T (2004) Interinstrument consistency of the Yamax Digi-Walker pedometer in elementary school-aged children. Measur Phys Ed Exerc Sci $\mathbf{8}$, 109-116.

29. Tudor-Locke R, Pangrazi C, Corbin W, Rutherford S \& Vincent S (2004) BMI-referenced standards for recommended pedometer-determined steps/day in children. Prev Med 38, 857-864.

30. Cole T, Freeman J \& Preece M (1995) Body mass index reference curves for the UK, 1990. Arch Dis Child 73, 25-29.

31. Sallis J, Grossman R, Pinski R, Patterson T \& Nader P (1987) The development of scales to measure social support for diet and exercise behaviors. Prev Med 16, 825-836.

32. Pan H \& Cole T (2007) ImsGrowth, a Microsoft Excel add-in to access growth references based on the LMS method. Version 2.2. 2007. http://homepage.mac.com/ tjcole/FileSharing1.html (accessed March 2008).

33. Gibson S, Lambert J \& Neate D (2004) Associations between weight status, physical activity, and consumption of biscuits, cakes and confectionery among young people in Britain. Nutr Bull 29, 301-309.

34. Cole T, Flegal K \& Jackson A (2007) Body mass index cut offs to define thinness in children and adolescents: international survey. BMJ 335, 194.

35. Duncan J, Schofield G \& Duncan E (2007) Step count recommendations for children based on body fat. Prev Med 44, 42-44.

36. Department of Health (1991) Dietary Reference Values of Food Energy and Nutrients for the United Kingdom. Report on Health and Social Subjects no. 41. London: The Stationery Office.

37. Gregory J \& Lowe S (2000) National Diet and Nutrition Survey: Young People Aged 4 to 18 Years. London: The Stationery Office.

38. Prochaska J \& Sallis J (2004) Reliability and validity of a fruit and vegetable screening measure for adolescents. J Adolesc Health 34, 163-165.

39. Margetts B \& Nelson M (1997) Design Concepts in Nutritional Epidemiology. Oxford: Oxford University Press.

40. Cole T, Bellizzi M, Flegal K \& Dietz W (2000) Establishing a standard definition for child overweight and obesity worldwide: international survey. BMJ 320, 1240-1243.

41. Department of Health (2007) Obesity guidance for healthy schools co-ordinators and their partners. http:// www.dh.gov.uk/en/Publicationsandstatistics/Publications/ PublicationsPolicyAndGuidance/DH_063507 (accessed December 2007).

42. Gunnell D, Frankel S, Nanchahal K, Peters T \& Smith G (1998) Childhood obesity and adult cardiovascular mortality: a 57-y follow-up study based on the Boyd Orr cohort. Am J Clin Nutr 67, 1111-1118.

43. James J, Thomas P, Cavan D \& Kerr D (2004) Preventing childhood obesity by reducing consumption of carbonated drinks: cluster randomised controlled trial. BMJ 328, 1237.

44. Paineau D, Beaufils F, Boulier A, Cassuto D, Chwalow J, Combris P, Couet C, Jouret B, Lafay L \& Laville M (2008) Family dietary coaching to improve nutritional intakes 
and body weight control: a randomized controlled trial. Arch Pediatr Adolesc Med 162, 34-43.

45. Cox M, Schofield G, Greasley N \& Kolt G (2006) Pedometer steps in primary school-aged children: a comparison of school-based and out-of-school activity. J Sci Med Sport 9, 91-97.

46. Flohr J, Todd M \& Tudor-Locke C (2006) Pedometerassessed physical activity in young adolescents. Res $Q$ Exerc Sport 77, 309-315.

47. Tudor-Locke C, Lee S, Morgan C, Beighle A \& Pangrazi R (2006) Children's pedometer-determined physical activity during the segmented school day. Med Sci Sports Exerc 38, $1732-1738$.

48. Jacobi C, Hayward C, de Zwaan M, Kraemer HC \& Agras WS (2004) Coming to terms with risk factors for eating disorders: application of risk terminology and suggestions for a general taxonomy. Psychol Bull 130, 19-65.

49. Bertheke Post G, De Vente W, Kemper H \& Twisk J (2001) Longitudinal trends in and tracking of energy and nutrient intake over 20 years in a Dutch cohort of men and women between 13 and 33 years of age: the Amsterdam Growth and Health Longitudinal Study. Br J Nutr 85, 75-85.

50. Lytle L, Himes J, Feldman H, Zive M, Dwyer J, Hoelscher D, Webber L \& Yang M (2002) Nutrient intake over time in a multi-ethnic sample of youth. Public Health Nutr 5, 319-328.

51. Livingstone M, Robson P \& Wallace J (2004) Issues in dietary intake assessment of children and adolescents. $\mathrm{BrJ}$ Nutr 92, 213-222.
52. Hill A \& Silver E (1995) Fat, friendless and unhealthy: 9 year old children's perception of body shape stereotypes. Int $J$ Obes Relat Metab Disord 19, 423-430.

53. Latner J \& Stunkard A (2003) Getting worse: the stigmatization of obese children. Obes Res 11, 452-456.

54. Woodward D, Ball P, Cumming F, Williams H, Hornsby H \& Boon J (1996) Adolescent usage of selected foods in relation to their perceptions and social norms for those foods. Appetite 27, 109-117.

55. Baranowski $\mathrm{T}$ (1997) Families and health in action. In Handbook of Health Behavior Research I: Personal and Social Determinants, vol. 1, pp. 179-205 [D Gochman, editor]. New York: Plenum Press.

56. Cullen K, Rittenberry L, Olvera N \& Baranowski T (2000) Environmental influences on children's diets: results from focus groups with African-, Euro- and, Mexican American children and their parents. Health Educ Res 15, 581-590.

57. French S, Story M, Hannan P, Breitlow K, Jefferey R, Baxter J \& Snyder M (1999) Cognitive and demographic correlates of low fat vending snack choices among adolescents and adults. J Am Diet Assoc 99, 471-475.

58. Taylor W, Baranowski T \& Sallis J (1994) Family determinants of childhood physical activity: a social-cognitive model. In Advances in Exercise Adherence, vol. 1, pp. 319-342 [R Dishman, editor]. Champaign, IL: Human Kinetics.

59. Purslow L, Hill C, Saxton J, Corder K \& Wardle J (2008) Differences in physical activity and sedentary time in relation to weight in 8-9 year old children. Int J Behav Nutr Phys Act 5, 1028-1032. 